Aksaray University
Journal of Science and Engineering
e-ISSN: 2587-1277
http://dergipark.gov.tr/asujse
http://asujse.aksaray.edu.tr

Research Article

\title{
Life Prediction of Spur Gear Under Fully Reversed Loading Using Total Life Approach and Crack-Initiation Method in FEM
}

\author{
J. Purushottam Karthik ${ }^{1, *}$, J. Rangaraya Chowdary ${ }^{1}$, C. Tara Sasanka ${ }^{1}$, D. Sameer Kumar ${ }^{2}$ \\ ${ }^{1}$ Department of Mechanical Engineering, R.V.R.\&J.C. College of Engineering, Guntur, India \\ ${ }^{2}$ Bapatla Engineering College, Bapatla, India
}

-Received Date: Dec 17, 2018

-Revised Date: Jul 22, 2019

-Accepted Date: Nov 11, 2019

-Published Online: Dec 05, 2019

\begin{abstract}
This paper focus on the comparative fatigue life prediction of spur gears based on finite element method under fully reversed load conditions. Gears being the vital components of any automobiles, power generation systems and in heavy machinery industries, need to have good fatigue properties such as fatigue life, endurance limit and fatigue strength for better life and performance of the equipment or machinery. Therefore, the main aim of this study is to simulate fully reversed loading conditions in the fatigue life prediction on general gear materials, SAE materials like ALSI4027, SAE1045-450-QT, SAED 5506 and SAE5160-825-QT. The finite element method (FEM) has been performed on the gear models to observe the distribution of stress and damage. A comparison was made on the fatigue life and the results were analyzed. Finally, conclusions were given.
\end{abstract}

\section{Keywords}

Fatigue life; constant amplitude proportional loading; Spur gear; FEM

\section{INTRODUCTION}

Gears are the most important elements for power transmission in the modern world [1,2]. They vary from small sizes used in the watches to the big gears used in speed reducers etc... So, the applications of gears in real word applications is massive. But gears suffer from four major

* Corresponding Author: J.P. Karthik, chandrakalachari@gmail.com 
failure modes such as tooth bending fatigue, contact fatigue, surface wear and scoring. Tooth breakage is clearly the worst among the all, since the gear could have seriously hampered operating condition or even be destroyed. So, the stress in the tooth should always be carefully studied in all practical gear application. The fatigue process in gears consists of crack initiation and crack propagation. The crack initiation period generally accounts for the most of service life, especially in high cycle fatigue [3]. The most common reasons for failure of gears are short-term overload, material defects, defects due to mechanical or thermal treatment and material fatigue.

Sameer et al. reported the importance of material selection and used MADM methods to find the suitable material among the compared materials [4]. It is observed that material selection plays a significant role as wrong selection of materials lead to failure. J.P. Karthik et al. tried to predict Material Selection under severe non constant amplitude loading conditions which play a major role in the fatigue failure $[5,6]$. The initial crack was first generated then propagates under impulsive loading until some critical length is reached and complete tooth breakage occurs. The service life of a gear with a crack in the tooth root can be determined experimentally or numerically (e.g. with finite element method). The fatigue life of components subjected to sinusoidal loading can be estimated by using cumulative damage theories. The model of Spur gear is shown in Fig. 1.

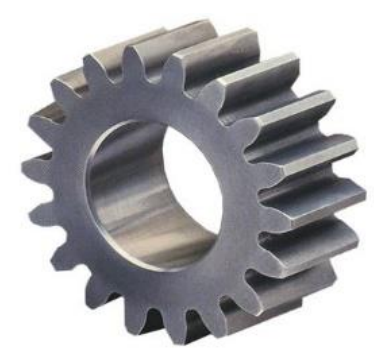

Figure 1. Model of spur gear.

Finite element simulations are popular in recent times as these predict the material behavior most approximately and save the time of industrialists doing research. Several authors [7, 8] used FEA based analyses software to predict the behavior of modals. Therefore, this paper confers to the selection and prediction of life and damage of spur gear under fully reversed loading for the given cyclic and physical properties of given materials using FEA Principles.

\section{FATIGUE ANALYSIS}

The fatigue analysis is used to compute the fatigue life of a component under repetitive loading and to predict the damage areas in components. Necessary inputs for the fatigue analysis are the material properties, loading history. 


\subsection{Material properties}

ALSI 4027 is the general material applied to spur gears for power transmission in automobiles. Materials like SAE1045-450-QT, SAE5160-825-QT has high tensile strength and yield strength compared to general material. Bandara and Ranjith did a research study in fatigue strength prediction formulae for steel [9]. The composition of materials used for Gears in the present study are given in Table 1.

Table 1. Materials composition

\begin{tabular}{|c|c|c|c|c|c|}
\hline Material & Si \% & S\% & C\% & Mn\% & P\% \\
\hline ALSI 4027 & 0.34 & 0.04 & 0.25 & 0.70 & 0.04 \\
\hline SAE1045-450 & 0.32 & 0.04 & 0.23 & 0.27 & 0.034 \\
\hline SAE5160-825-QT & 0.35 & 0.04 & 0.40 & 0.90 & 0.04 \\
\hline
\end{tabular}

\subsection{Loading histories}

Loading is another major input for the finite element based fatigue analysis. Unlike static stress, fatigue damage occurs when stress at a specific point changes over time. There are four classes of fatigue loading videlicet. [9];

- Constant amplitude, proportional loading.

- Constant amplitude, non-proportional loading.

- Non-constant amplitude, proportional loading.

- Non-constant amplitude, non-proportional loading.

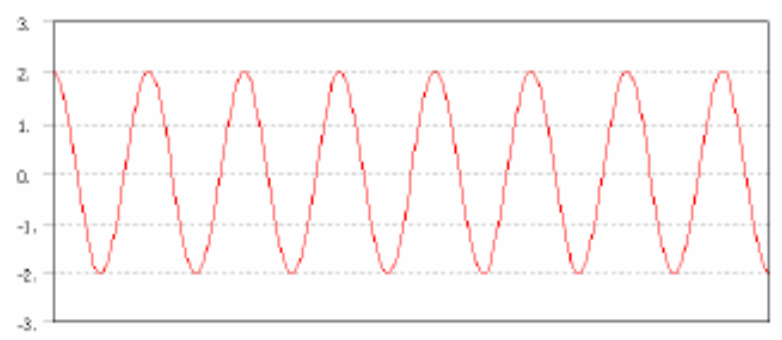

Figure 2. Fully reversed cycle at constant amplitude load [10]

Constant Amplitude, fully reversed loading within the fatigue Module uses a "quick counting" technique to substantially reduce runtime and memory in ANSYS as observed from Fig. 2. Loading is of constant amplitude because only one set of FE stress results along with a loading ratio is required to calculate the alternating and mean values. The loading ratio is expressed as the ratio of the second load to the first load ( $\mathrm{LR}=\mathrm{L} 2 / \mathrm{L} 1)$. Since loading is proportional, looking at a single set of FE results can identify critical fatigue locations for this constant amplitude fully reversed loading. The stress life analysis and strain life analysis can be selected in fatigue 
tool. Theoretically Goodman, Gerber equation are used in stress life analysis and SWT Morrow in strain life analysis.

\section{FATIGUE ANALYSIS ALGORITHM}

Manson conducted various case studies on fatigue analysis [11] with the calculation of static and dynamic analysis, and fatigue life estimation. J.P. Karthik [5] conducted fatigue analysis on truck wheel rim [2] under fully reversed loading and predicted the life. Based on these studies an integrated FE based durability analysis is considered a complete analysis of an entire component. Fatigue life can be estimated for every element in the finite element model for better understanding and contour plots of life can also provide the major information to researchers. The schematic algorithm of the integrated finite element based fatigue life prediction analysis is shown in Fig. 3.

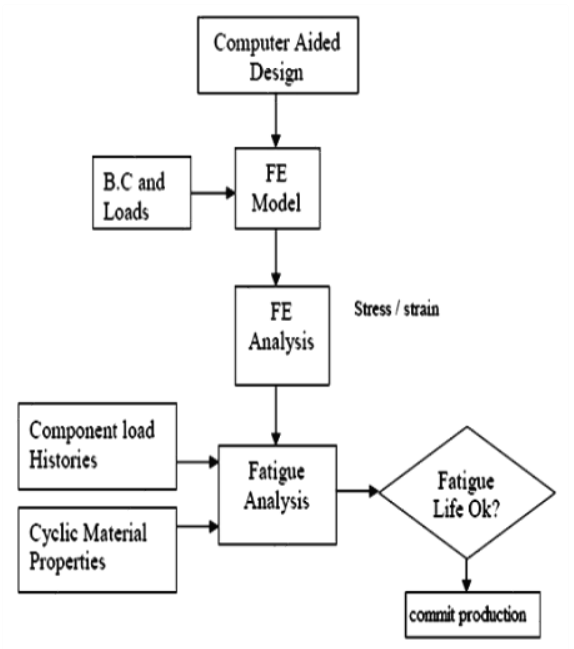

Figure 3. The finite element based fatigue analysis Cycle [6]

\subsection{Computer Aided Design}

In the computer aided design the complete design of the gear (Spur) with its specifications, like number of teeth, pitch diameter, type of gear has been taken into consideration. Basing on all the possible criteria's various designs have been stimulated and an optimum design model is made for different materials considered and are subjected to fatigue loading for clear study.

\subsection{Finite Element Model and Analysis}

Later the model is subjected to various kinds of loads at various points of the design and then this model is sent to finite element analysis under the same loads and it is analyzed for various stresses. This analysis is so done to determine the various stresses that are acting at different points and at different positions for all the different gear materials taken into consideration 
while designing and finally a comparative study on all the kinds is made. Numerical techniques are necessary to simulate the physical behaviour and to evaluate the structural integrity of the different designs. The objective of the current study is to calculate the fatigue life of a spur gear using total life and crack initiation methods, to investigate the effect of mean stress on fatigue life and the probabilistic nature of fatigue on the S-N curve via the design criteria.

\subsection{Fatigue Analysis}

This stimulated model made by optimal designing after Finite Element Analysis is subjected to Fatigue loading for analysis of Fatigue failures. Initially the component i.e., the gear is subjected to Histories and then Reversed loads are acted upon it. When the gears are in mesh the Reversed loads are acted upon the gears and the fatigue life is calculated. At this condition the life of gears is found and if it's in acceptable range it's finalized and is sent for production. The mechanical properties for the materials are mentioned in Table 2

Table 2. Mechanical and cyclic properties of SAE1045-450-QT, SAE5160-825-QT and ALSI4027 [5, 6].

\begin{tabular}{|c|c|c|c|c|}
\hline \multirow{2}{*}{ Properties } & \multicolumn{4}{|c|}{ Materials } \\
\hline & SAE1045 -450-QT & SAE5160 -825-QT & ALSI4027 & SAED -5506 \\
\hline Yield strength(Mpa) & 1550 & 1860 & 325 & 500 \\
\hline $\begin{array}{l}\text { Ultimate-tensile } \\
\text { strength }(\mathrm{Mpa})\end{array}$ & 2070 & 2239 & 515 & 863 \\
\hline Elastic modulus(Mpa) & 207000 & 207000 & 210000 & 207000 \\
\hline $\begin{array}{l}\text { Fatigue strength } \\
\text { coefficient }\left(\mathrm{S}_{\mathrm{f}}\right)\end{array}$ & 2200 & 3047 & 1030 & 1030 \\
\hline $\begin{array}{l}\text { Fatigue strength } \\
\text { exponent(b) }\end{array}$ & -0.08 & -0.10 & -0.083 & -0.083 \\
\hline $\begin{array}{l}\text { Fatigue ductility } \\
\text { exponent(c) }\end{array}$ & -0.69 & -0.79 & -0.722 & -0.722 \\
\hline $\begin{array}{l}\text { Fatigue ductility } \\
\operatorname{coefficient}\left(\varepsilon_{\mathrm{f}}^{\prime}\right)\end{array}$ & 1.22 & 0.13 & 0.813 & 0.813 \\
\hline $\begin{array}{c}\text { Cyclic-strain hardening } \\
\text { exponent(n') }\end{array}$ & 0.1 & 0.10 & 0.15 & 0.15 \\
\hline $\begin{array}{l}\text { Cyclic strength } \\
\text { coefficient }(\mathrm{k})\end{array}$ & 2500 & 3498 & 1230 & 1230 \\
\hline
\end{tabular}

\subsection{Fatigue analysis methods}

Fatigue analysis can be carried out one of three basic approaches i.e., the total life (stress-life) approach and crack propagation approach, the crack initiation approach. The total-life (stresslife) approach was first applied over a hundred years ago and considers nominal elastic stresses and how they are related to life. The crack-initiation (stress-life) approach considers elasticplastic local stresses and strains. It represents more fundamental approach and is used to determine the number of cycles required to initiate a small engineering cracks. Crackpropagation or linear elastic fracture mechanics (LEFM) approach is used to predict how 
quickly pre-existing cracks grow and to estimate how many loading cycles are required to grow these to a critical size when catastrophic failure would occur. First two methods are used in this study and briefly discussed these two methods in the following sections.

The fatigue total-life (S-N) approach is usually used for the life prediction of components subjected to high cycle fatigue, where stresses are mainly elastic. This approach emphasizes nominal stresses rather than local stresses. It uses the material stress-life curve and employs fatigue notch factors to account for stress concentrations, empirical modification factors for surface finish effects and analytical equations such as modified Goodman and Gerber equations are given below [12].

$$
\begin{aligned}
& \frac{\sigma_{a}}{S_{e}}+\frac{\sigma_{m}}{S_{u}}=1 \\
& \frac{\sigma_{a}}{S_{e}}+\left(\frac{\sigma_{m}}{S_{u}}\right)^{2}=1
\end{aligned}
$$

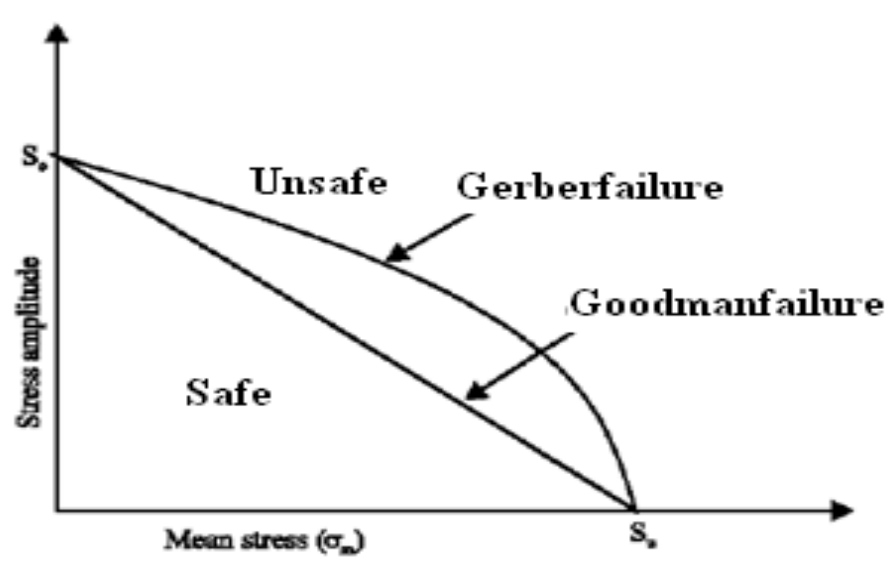

Figure 4. Representation of mean stress correction methods.

Where $\sigma_{\mathrm{a}}, \mathrm{S}_{\mathrm{e}}, \sigma_{\mathrm{m}}$ and $\mathrm{S}_{\mathrm{a}}$ are the alternating stress in the presence of mean stress, alternating stress for equivalent completely reversed loading, the mean stress and the ultimate tensile strength, respectively. The typical representation of these mean stress correction method shown in fig 4. The Basquin equation showed that alternating stress verses number of cycles to failure $(\mathrm{S}-\mathrm{N})$ in finite life region could be represented as a log-log linear relationship. Basquin equation was then used to obtain the fatigue life using the material properties listed in Table 2. S-N approach uses to estimate the fatigue life for combined loading by determining an equivalent axial stress [13] using one of the common failure criteria such as Tresca, Von-Mises, or maximum principal stress. The $\mathrm{S}-\mathrm{N}$ equation is mathematically given by:

$$
S_{e}=\sigma_{f}^{\prime}\left(2 N_{f}\right)^{b}
$$


Where $S_{e}, \sigma_{f}^{\prime}, 2 N_{f}$ and $b$ are the stress amplitude, the fatigue strength coefficient, the reversals to failure and the fatigue strength exponent, respectively. (See Fig. 5). Shows comparison between the two materials with respect to $\mathrm{S}-\mathrm{N}$ behaviour. It can be seen that these curves exhibit different life behaviour depending on the stress range experienced. From the Fig. 5, it is observed that in the long life area (high cycle fatigue), the different is lower while in the short life area (low cycle fatigue), the difference is higher. An important aspect of the fatigue process is plastic deformation. Fatigue cracks initiate from the plastic straining in localized regions significant localized plastic deformation is often present, total-life approach doesn't account for plastic strain. Main advantage of this method is that it accounts for changes in local mean and residual stresses.

\section{Stress life (S-N) plot}
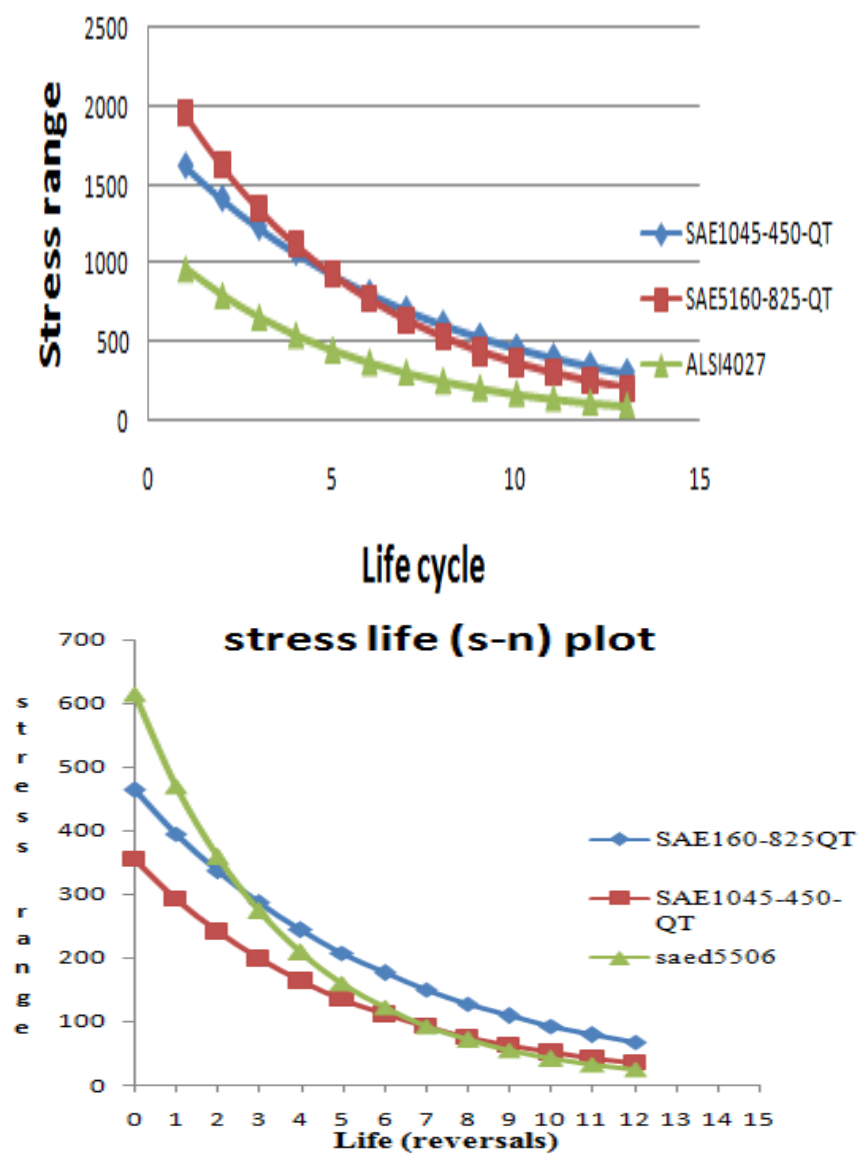

Figure 5. a) Stress-life (Stress-Number of cycles) plot for SAE5160-825-QT, SAE1045-450-QT and ALSI4027,

b) Stress-life (Stress-Number of cycles) plot for SAE5160-825-QT, SAE1045-450-QT and SAED5506

Therefore, cyclic strain-controlled fatigue method could better characterize the fatigue behaviour of materials than cyclic strain controlled fatigue particularly in notched members where the significant localized plastic deformation is often present. In the crack initiation approach the plastic strain is directly measured and quantified. The total-life approach does not 
account for plastic strain one of the main advantages of this method is that it accounts for changes in local mean and residual stresses. In strain-life when the load history contains large over loads, significant plastic deformation can exist, particularly at stress concentrations and the load sequence effects can be significant. In these cases, the crack initiation approach is generally superior to the total life approach for fatigue life prediction analysis. However, when the load levels are relatively low such that the resulting strains are mainly elastic, the crack initiation and total life approaches usually result in similar predictions.

The fatigue crack initiation approach involves the techniques for converting load history, geometry and material properties (monotonic and cyclic) input in to the fatigue life prediction In this study, it was observed that the local strain approach using the Smith-Watson-Topper (SWT) strain-life model is able to represent and to estimate many factors explicitly. These include mean stress effects, load sequence effects above and below the endurance limit and manufacturing process effects such as surface roughness and residual stresses. The fatigue resistance of metals can be characterized by a strain life curve. These curves are derived from the polished laboratory specimens tested under completely reversed strain control. The relationship between the total strain amplitude $(\Delta \varepsilon / 2)$ and reversals to failure $\left(2 \mathrm{~N}_{\mathrm{f}}\right)$ can be expressed in following form.

$$
\frac{\Delta \varepsilon}{2}=\frac{\sigma_{f}^{\prime}}{E}\left(2 N_{f}\right)^{b}+\varepsilon_{f}^{\prime}\left(2 N_{f}^{c}\right)
$$

Where, $\mathrm{N}_{\mathrm{f}}$ is the fatigue life; $\sigma_{\mathrm{f}}^{\prime}$ is the fatigue strength coefficient; $\mathrm{E}$ is the modules of elasticity; $\varepsilon_{\mathrm{f}}^{\prime}$ is the fatigue ductility coefficient and $\mathrm{c}$ is fatigue ductility exponent. The strain life cures for the material as shown in Fig. 6 for life cycles based up on Eq. 4. Morrow suggested that mean stress effects are considered by modifying the elastic term in the strain-life equation by mean stress $\left(\sigma_{\mathrm{m}}\right)$. From mean stress was estimated Strain life cures are plotted as show in Fig. 7 for life cycles based up on Eq. 5 .

$$
\varepsilon_{a}=\frac{\sigma_{f}^{\prime}-\sigma_{m}}{E}\left(2 N_{f}\right)^{b}+\varepsilon_{f}^{\prime}\left(2 N_{f}\right)^{c}
$$

Smith [14] was introduced another mean stress model which is called SWT mean stress correction model. It is mathematically defined by

$$
\sigma_{\max } \varepsilon_{a} E=\left(\sigma_{f}^{\prime}\right)^{2}\left(2 N_{f}\right)^{2 b}+\sigma_{f}^{\prime} \varepsilon_{f}^{\prime}\left(2 N_{f}\right)^{b+c}
$$

Where, $\sigma_{\max }$ is the maximum stress and $\varepsilon_{\mathrm{a}}$ is the strain amplitude. Strain life cures are plotted as show in Fig. 8 for life cycle based up on above equation Eq. 6. 

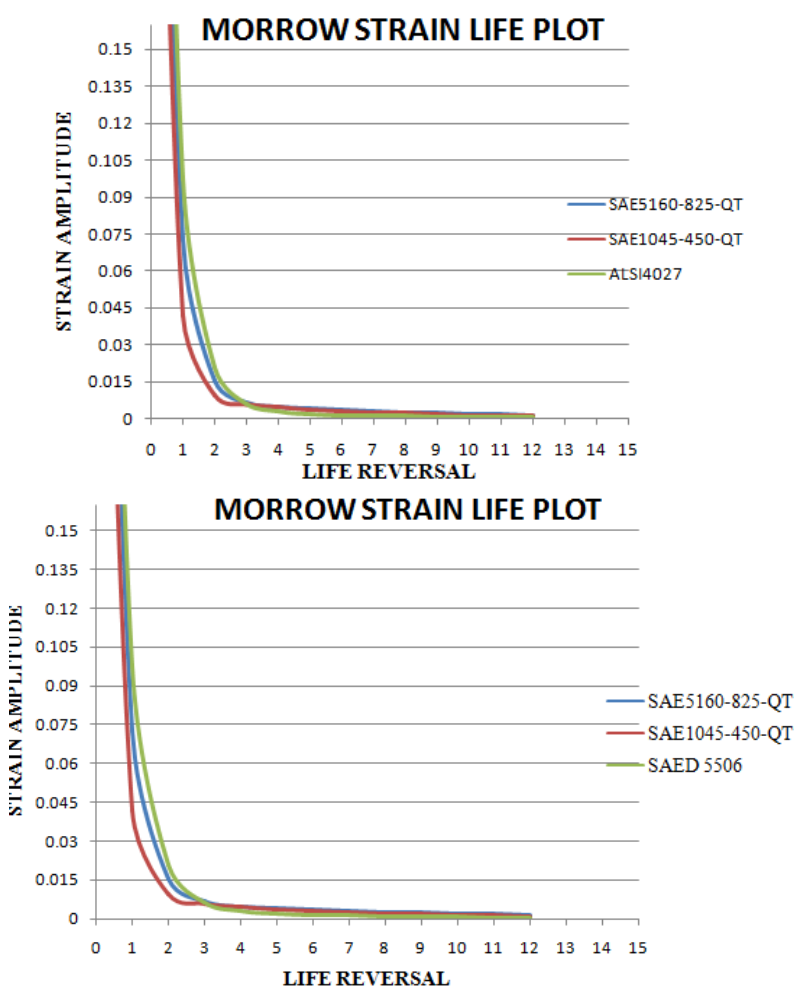

Figure 6. a) Morrow Strain-life (S-N) plot for SAE5160-825-QT, SAE1045-450-QT and ALSI4027,

b) Morrow Strain-life (S-N) plot for SAE5160-825-QT, SAE1045-450-QT and SAED 5506.
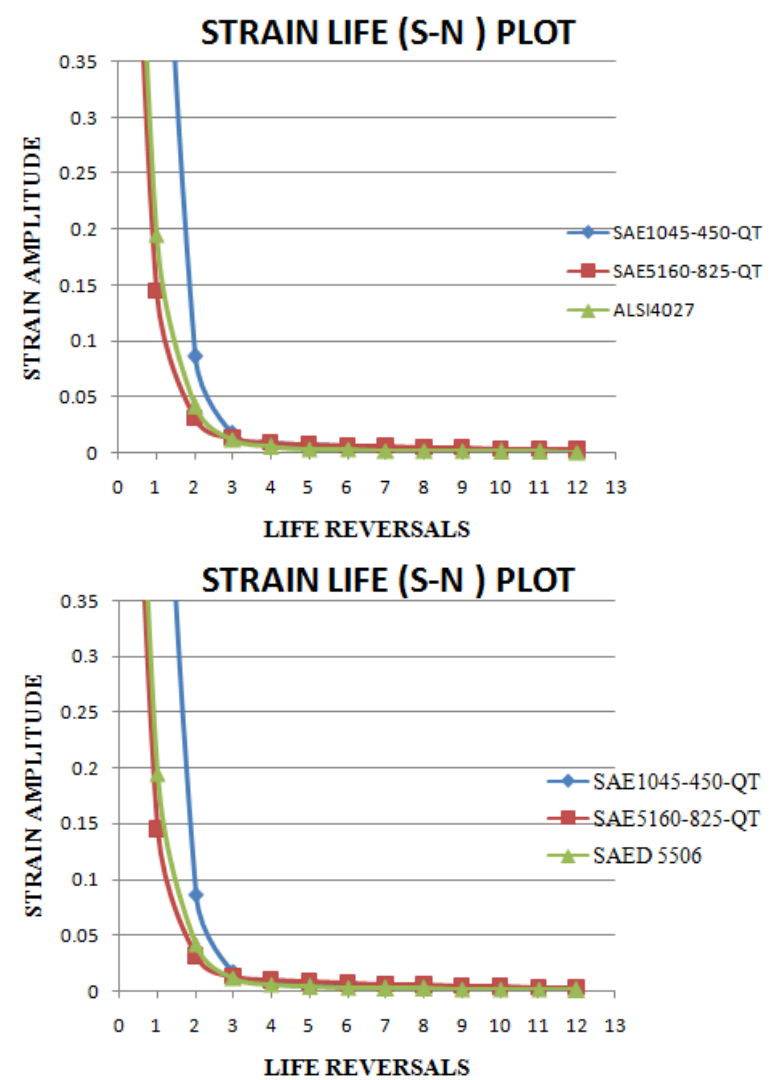

Figure 7. a) Strain-life (S-N) plot for SAE5160-825-QT, SAE1045-450-QT and ALSI4027,

b) Strain-life (S-N) plot for SAE5160-825-QT, SAE1045-450-QT and SAED 5506 


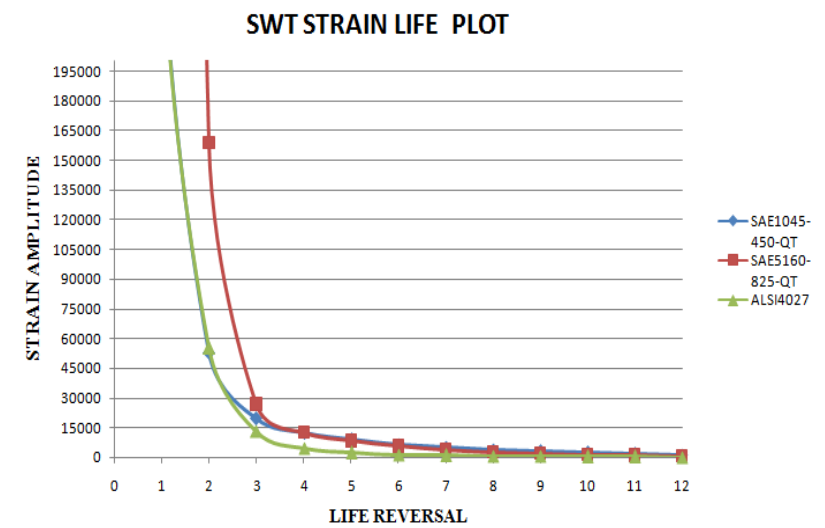

SWT STRAIN LIFE PLOT

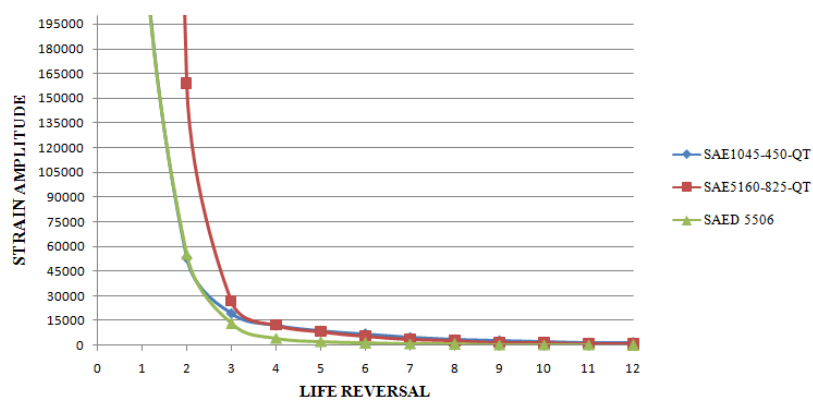

Figure 8. a) SWT Strain-life (S-N) plot for SAE5160-825-QT, SAE1045-450-QT and ALSI4027,

b) SWT Strain-life (S-N) plot for SAE5160-825-QT, SAE1045-450-QT and SAED 5506

\section{BOUNDARY CONDITIONS AND LOADING}

\subsection{Modelling}

Equation ally driven spur gear was drawn in CATIA V5. By considering following parameters

- No of teeth 25

- Pressure angle 200

- Module $3.5 \mathrm{~mm}$

- Pitch circle $40 \mathrm{~mm}$

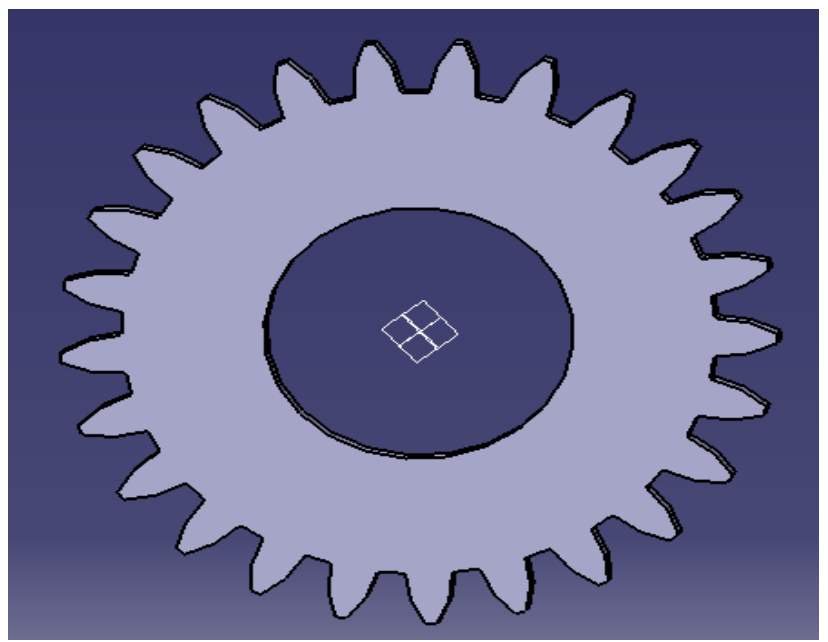

Figure 9. Model design of a Spur Gear in CATIA. 


\subsection{Meshing}

Fine meshing of tetrahedron type (Solid 187) is done to get the accurate results of contact stress. Total nodes-130158, Total elements-27192.

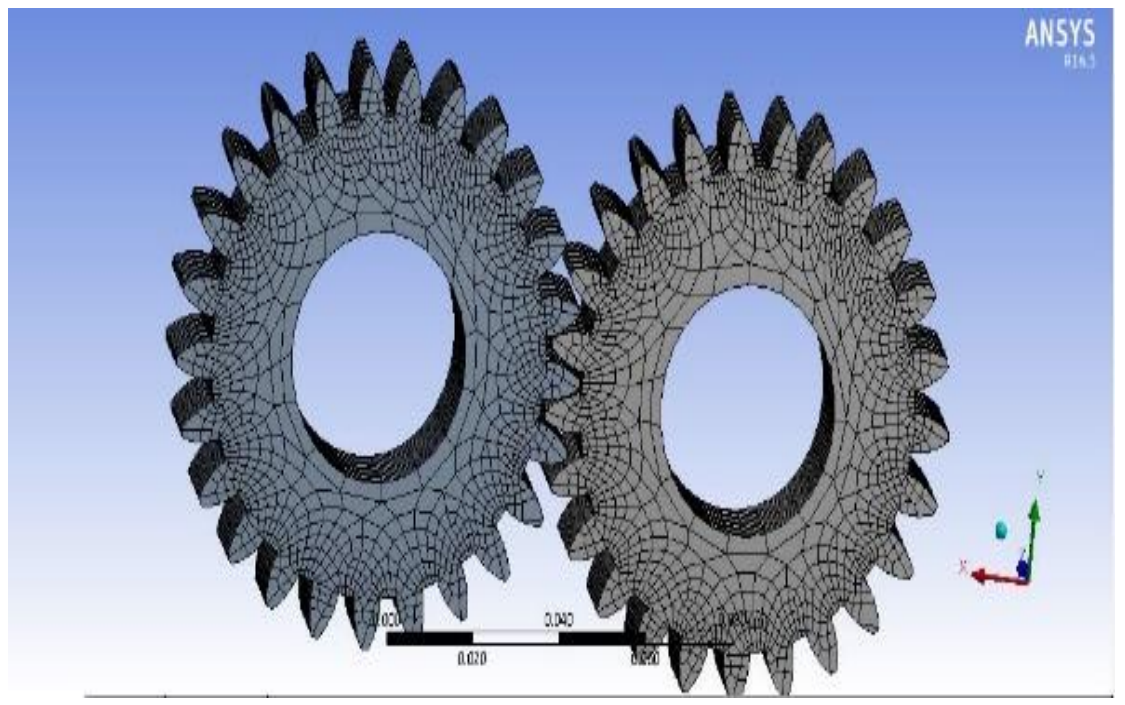

Figure 10. Finite element model of Gears.

\subsection{Boundary Condition}

Tangential load of $2315 \mathrm{~N}$ is applied at the point of contact during the mating of the two gears. Frictionless support and the moment of $194.46 \mathrm{~N}-\mathrm{m}$ to the gear and moment of $76.395 \mathrm{~N}-\mathrm{m}$ to the pinion in opposite direction is given.

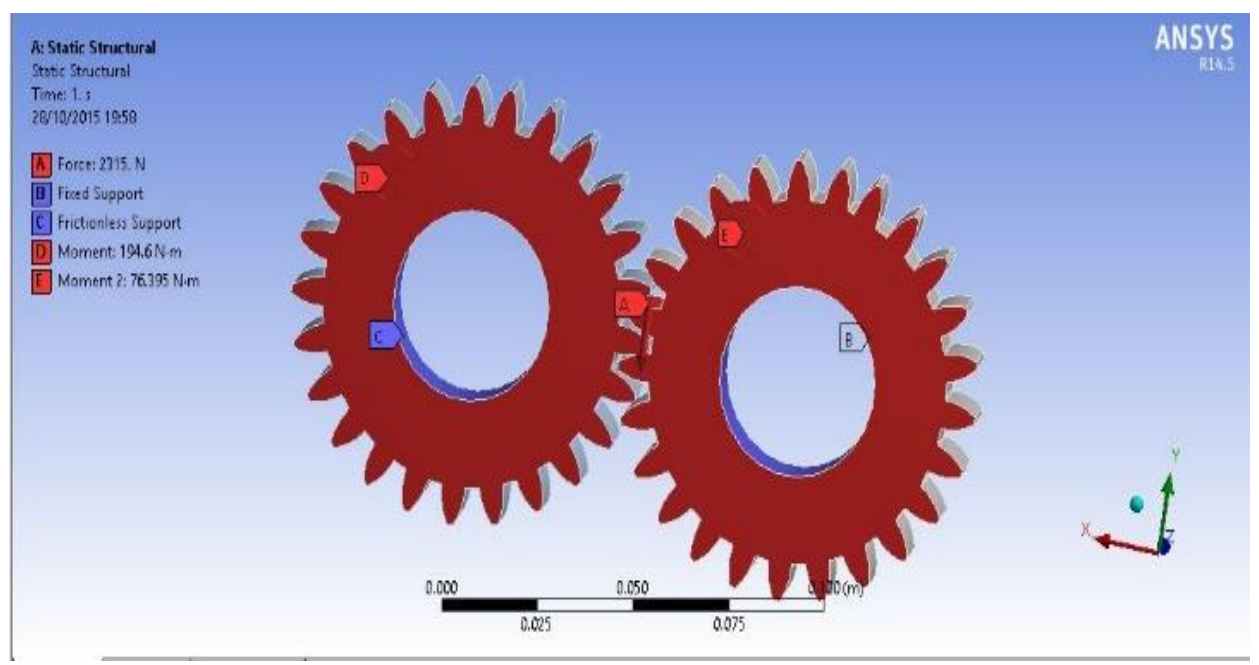

Figure11. Boundary conditions.

\section{RESULTS AND DISCUSSION}

The life of gear was calculated using ANSYS software by considering suitable boundary conditions. 


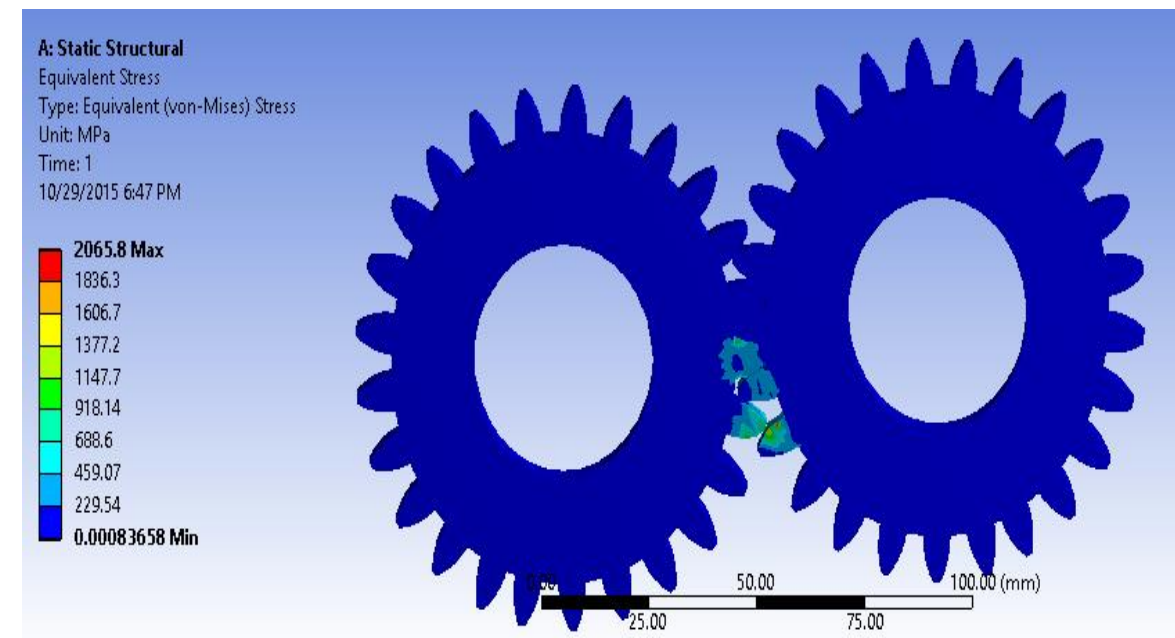

Figure 12. Equivalent stresses of the gear .

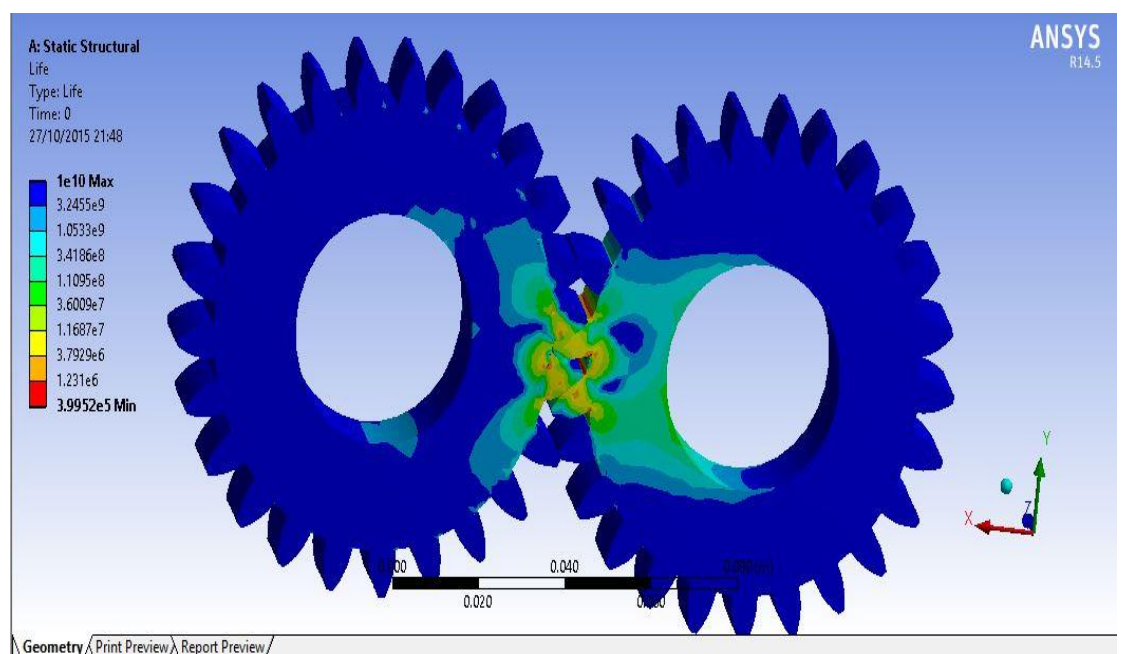

Figure 13. Stress Life value of SAE1045-450-QT

For the above analysis figure of Spur Gear of SAE1045-450-QT, the minimum value under fully revered loading is (3.9925E5).

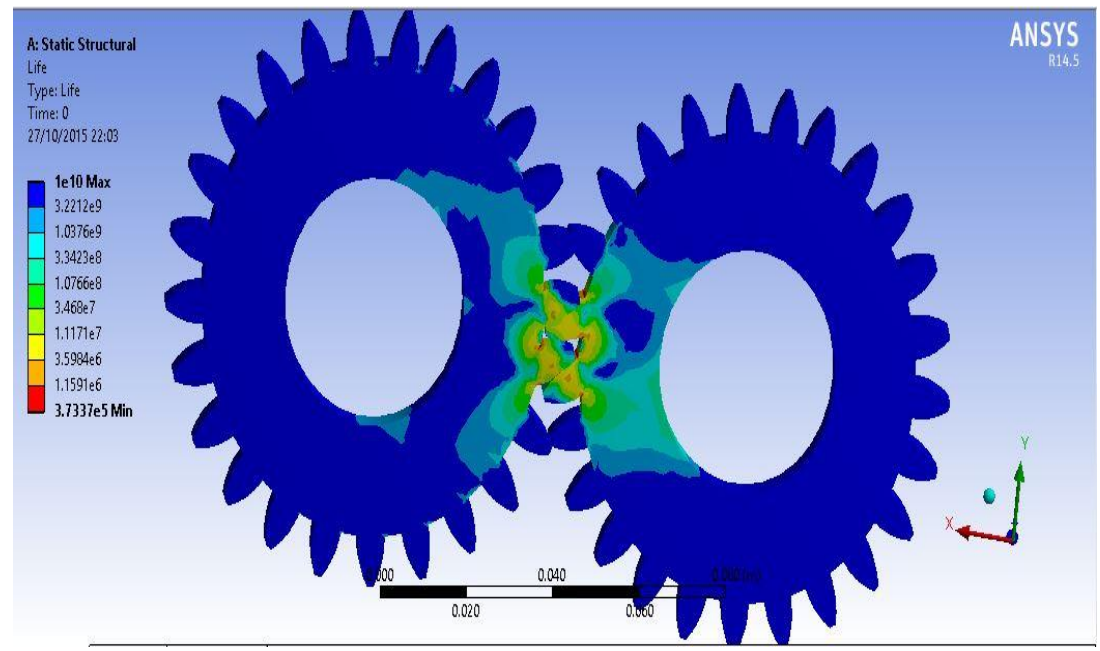

Figure 14. Stress Life Value of ALSI4027. 
For the above analysis figure of Spur Gear of ALSI4027, the minimum value under fully revered loading is $(3.7737 \mathrm{E} 5)$.

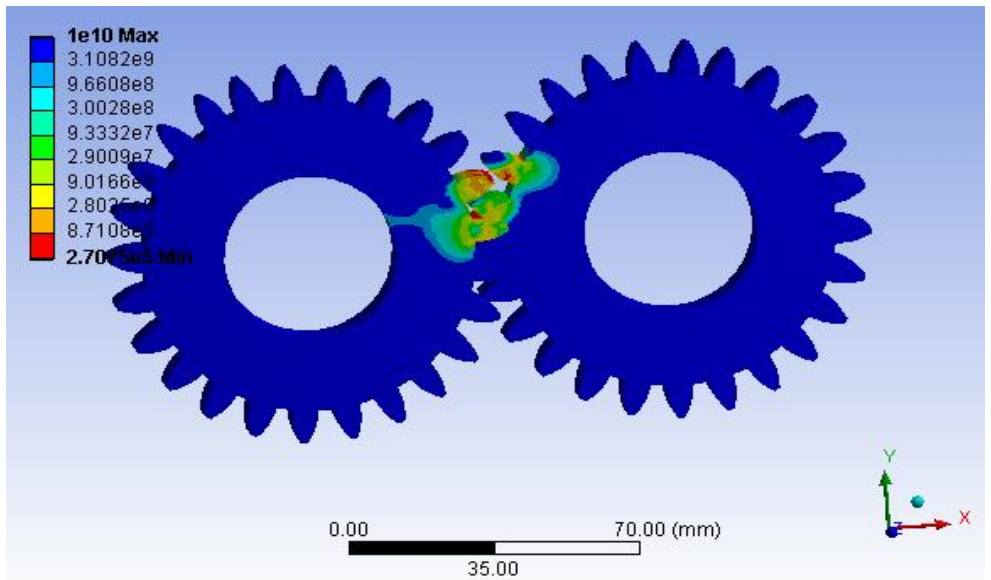

Figure 15. Stress Life value of SAE5160-825QT.

For the above analysis figure of Spur Gear of SAE5160-825QT, the minimum value under fully revered loading is $(2.70 \mathrm{E} 5)$.

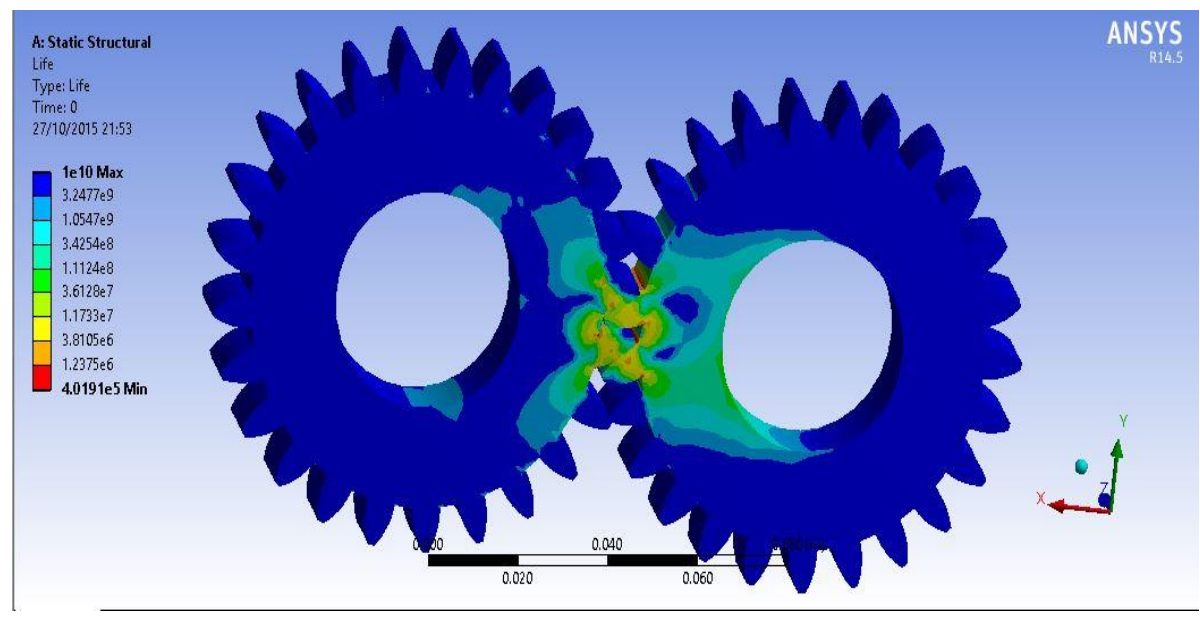

Figure 16. Stress Life value of SAED-506.

For the above analysis figure of Spur Gear of SAED-5506, the minimum value under fully revered loading is $(4.091 \mathrm{E} 5)$.

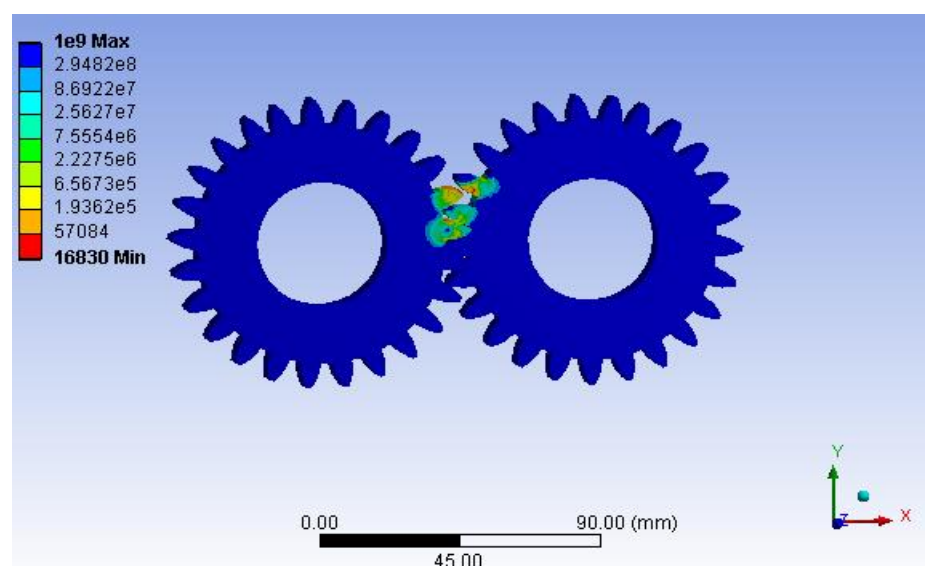

Figure 17. Strain life value ALSI4027. 
For the above analysis figure of Spur Gear of ALSI4027, the minimum value under fully revered loading is 16830 .

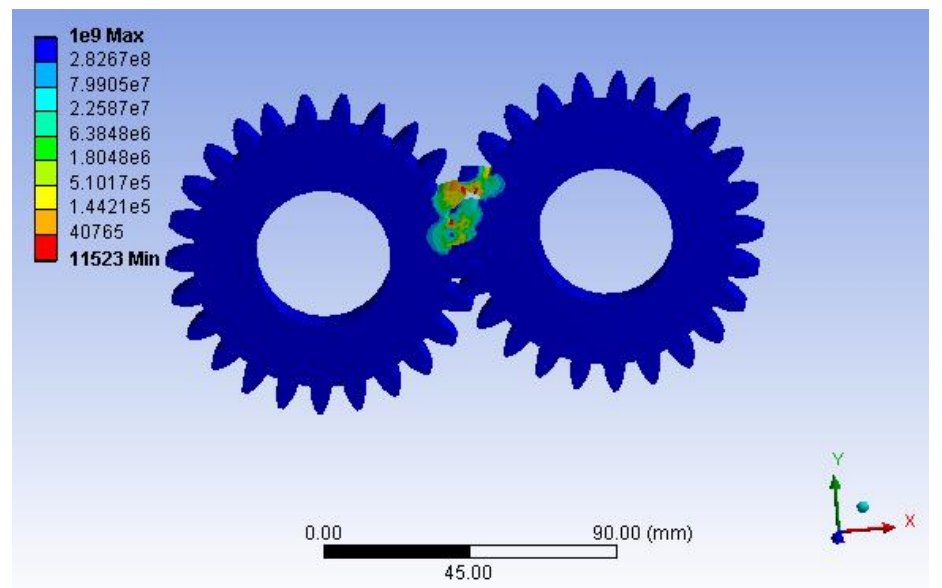

Figure 18. Strain life value SAE5160-825QT.

For the above analysis figure of Spur Gear of SAE5160-825QT, the minimum value under fully revered loading is 11523 .

The Palmgren-Miner rule states that failure occurs when

$$
\sum_{i=1}^{I} \frac{n_{i}}{N_{i}}=1
$$

Where $n_{i}$ is the number of applied load cycles of type $i$, and $N_{i}$ is the pertinent fatigue life. The damage induced in the $i^{\text {th }}$ load cycle as

$$
D_{i}=\frac{1}{N_{i}}
$$

Then, Palmgren - Miner's rule states that fatigue failure occurs when

$$
\sum_{i=1}^{I} D_{i}=1
$$

The Von-Mises equivalent stresses (see Fig.12) are used for subsequent fatigue life analysis and comparisons. Figures 13-16 represents life values of gear based on stress equations i.e. Goodman, Gerber equations. Figures 17, 18 represents life values of spur gear based on strain equation i.e. SWT, Morrow equations. However, in Table 3-4, it can be seen that when using the loading sequences are predominantly tensile in the nature; the Goodman approach is more conservative. Gerber mean stress correction has been found to give conservative when the time histories predominantly zero mean. The three-dimensional cycle histogram and corresponding damage histogram for materials using fully reversed loading histories is shown in the Figs. 19 and 20. Fig. 19 shows the results of the rain flow cycle count for the component. It can be seen that a lot of cycles with a low stress range and fewer with a high range 


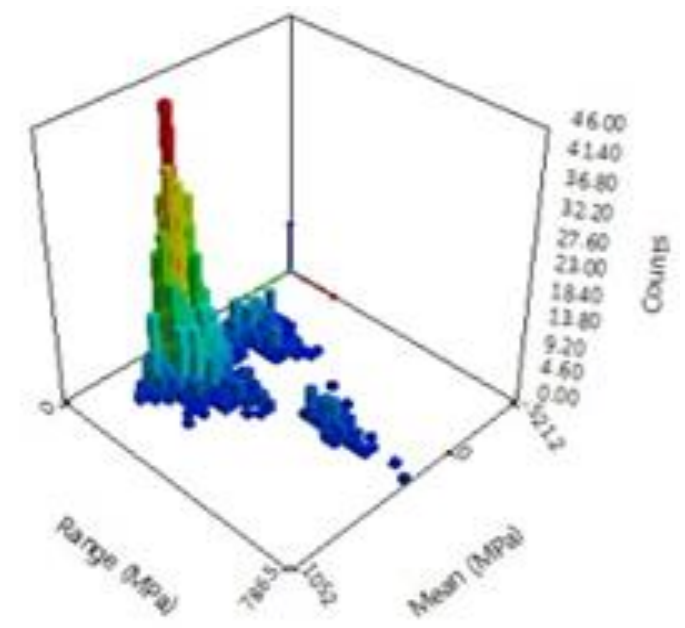

Figure 19. Rain flow matrix.

The height of each tower represents the number of cycles at that particular stress range and mean. Each tower is used to obtain damage on the $\mathrm{S}-\mathrm{N}$ curve and damage is summed over all towers. Fig. 20 shows that lower stress ranges produced zero damage. It is also showed that the high stress ranges were found to give the most of the damage and a fairly wide damage distribution at the higher ranges which mean that it cannot point to a single event causing damage. Most realistic service situations involve nonzero mean stresses, it is, therefore, very important to know the influence that mean stress has on the fatigue process so that the fully reversed (zero mean stress) laboratory data are usefully employed in the assignment of real situations.

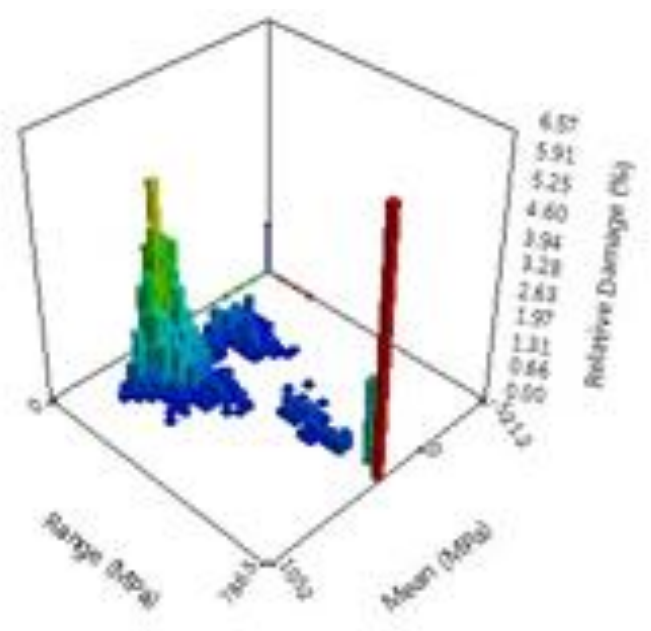

Figure 20. Damage matrix.

Table 3 and 4 represents predicted fatigue lives using total life approach and crack initiation approaches. 
Table 3. Fatigue life using total life approach.

\begin{tabular}{|c|c|c|c|}
\hline \multirow{2}{*}{$\begin{array}{c}\text { Materials } \\
\text { loading }\end{array}$} & \multicolumn{3}{|c|}{ Fully reverse loading in Mpa } \\
\cline { 2 - 4 } & No mean & Marrow & SWT \\
\hline SAE1045-450-QT & $100.5^{*} 10^{5}$ & $43.85^{*} 10^{5}$ & $58.85^{*} 10^{5}$ \\
\hline ALSI4027 & $110.586^{*} 10^{5}$ & $115.85^{*} 10^{5}$ & $85.65^{*} 10^{5}$ \\
\hline SAED5506 & $100.85^{*} 10^{5}$ & $41.85^{*} 10^{5}$ & $104.58^{*} 10^{5}$ \\
\hline SAE5160-825-QT & $165.3^{*} 10^{5}$ & $168.3 * 10^{5}$ & $152.3 * 10^{5}$ \\
\hline
\end{tabular}

Table 4. Fatigue life using crack initiation approach.

\begin{tabular}{|c|c|c|c|}
\hline \multirow{2}{*}{$\begin{array}{c}\text { Materials } \\
\text { loading }\end{array}$} & \multicolumn{3}{|c|}{ Fully reverse loading in Mpa } \\
\cline { 2 - 4 } & No mean & Goodman & Gerber \\
\hline SAE1045-450-QT & $3.9952^{*} 10^{5}$ & $3.83^{*} 10^{5}$ & $4.355^{*} 10^{5}$ \\
\hline ALSI4027 & $3.733^{*} 10^{5}$ & $3.65^{*} 10^{5}$ & $4.855^{*} 10^{5}$ \\
\hline SAED5506 & $4.0191 * 10^{5}$ & $3.16^{*} 10^{5}$ & $4.66^{*} 10^{5}$ \\
\hline SAE5160-825-QT & $2.87 * 10^{5}$ & $2.97 * 10^{5}$ & $2.71 * 10^{5}$ \\
\hline
\end{tabular}

\section{CONCLUSION}

The fatigue life was estimated based on Palmgren-Miner rule, which is a non-conservative SWT correction and Morrows methods. By comparing Table 3 and Table 4, we can observe that we have better results for SAE5160-825QT than SAE1045-450QT, ALSI4027. SAED5506. From Table 3 we can conclude that the life of as spur gear for material SAE5160-825QT in Gerber mean stress equation is $2.71 * 105$ which is sensitive. From Table 4 , we can conclude that the life of a spur gear for material SAE5160-825QT in morrow approach is $168.38 * 105$ which is sensitive. Therefore, the material SAE5160-825QT which is more conservative compared to other materials. In Table 3 Goodman equation is better in total life approach and Morrow equation in crack initiation approach. Therefore, SAE5160-825QT is better material and can be used for automobiles instead of ALSI4027.From the Figs. 12-14. SAE5160-825QT material has better result and more life than ALSI4027, similarly from Figs. 15-16. SAE5160-825QT has more life. It can be used for heavy loads and better power transmissions compared to general materials.

\section{REFERENCES}

[1] J.P. Karthik, T.R. Sai, S.S. Praneeth, International Journal of Advanced Design and Manufacturing Technology 9(3) (2016) 49-56.

[2] S.G.A. Hasan, G.S. Kumar, S.S. Fatima, International Journal of Engineering Sciences \& Research Technology 4(7) (2015) 523-534.

[3] X. Zheng, International Journal of Fatigue 23(9) (2001) 751-766. 
[4] D.S. Kumar, K.N.S. Suman, International Journal of Engineering and Manufacturing (IJEM) 4(2) (2014) 31-41.

[5] J.P. Karthik, D.M. Kumar, J.R. Chowdary, International Journal of Applied Science and Engineering 13(1) (2015) 69-79.

[6] J.P. Karthik, K.L. Chaitanya, C.T. Sasanka, International Journal of Advanced Science and Technology 46 (2012) 143-156.

[7] S-C. Hwang, J-H. Lee, D-H. Lee, S-H. Han, K-H. Lee, Mathematical and Computer Modelling 57(1-2) (2013) 40-49.

[8] Y-L. Lee, J. Pan, R. Hathaway, M. Barkey, Fatigue testing and analysis, theory and practice, UK: Elsevier Butterworth-Heinemann (2005).

[9] A. Kalani, R. Jain, International Journal of Mechanical Engineering and Technology (IJMET) 6(5) (2015) 82-91.

[10] S.S. Manson, Experimental Mechanics 5(4) (1965) 193-226.

[11]J.D. Morrow, Fatigue Properties of Metal Fatigue Design Handbook, Society of Automotive Engineers (1968).

[12]C.S. Bandara, S.C. Siriwardane, U.I. Dissanayake, R. Dissanayake, International Journal of Materials, Mechanics and Manufacturing 1(3) (2013) 256-260.

[13] K.N. Smith, P. Watson and T.H. Topper, Journal of Materials, JMLSA 5(4) (1970) 767 778.

[14] S.D. Galande, R.J. Patil, IPASJ International Journal of Mechanical Engineering (IIJME) 2(7) (2014) 25-31. 